\title{
Intra-abdominal aortic graft infection: prognostic factors associated with in-hospital mortality
}

\author{
Matthias Garot ${ }^{1}$, Pierre-Yves Delannoy ${ }^{1}$, Agnès Meybeck ${ }^{1}$, Béatrice Sarraz-Bournet ${ }^{2}$, PierVito d'Elia ${ }^{2}$, \\ Thibaud d'Escrivan ${ }^{3}$, Patrick Devos ${ }^{4}$ and Olivier Leroy ${ }^{5^{*}}$
}

\begin{abstract}
Background: Mortality associated with aortic graft infection is considerable. The gold standard for surgical treatment remains explantation of the graft. However, prognostic factors associated with early mortality due to this surgical procedure are not well-known.

Methods: Retrospective analysis of patients admitted in our center between January 2006 and October 2011 for aortic graft infection. The primary endpoint was in-hospital mortality. A bivariate analysis of characteristics of patients associated with in-hospital outcome was performed.

Results: Twenty five evaluable patients were studied. All patients were male. Their mean age was $67 \pm 8.4$ years. Most of them (92\%) had severe underlying diseases. An in situ prosthetic graft replacement, mainly using cryopreserved arterial allografts, was performed in all patients, excepted one who underwent extra-anatomic bypass. Causative organisms were identified in 23 patients (92\%). The in-hospital mortality rate was 48\%. Among pre-operative characteristics, age $\geq 70$ years, creatinine $\geq 12 \mathrm{mg} / \mathrm{L}$ and $C$ reactive protein $\geq 50 \mathrm{mg} / \mathrm{L}$ were significantly associated with in-hospital mortality. Hospital mortality rates increased with the number of risk factor present on ICU admission, and were 0\%, 14.3\%, 85.7\% and 100\% for 0, 1, 2 and 3 factors, respectively. The only intra-operative factor associated with prognosis was an associated intestinal procedure due to aorto-enteric fistula. SAPS II, SOFA score and occurrence of medical or surgical complications were postoperative characteristics associated with in-hospital mortality.
\end{abstract}

Conclusion: Morbidity and mortality associated with surgical approach of aortic graft infections are considerable. Age and values of creatinine and C Reactive protein on hospital admission appear as the most important determinant of in hospital mortality. They could be taken into account for guiding the surgical strategy.

Keywords: Aortic graft, Aortic surgery, Prosthetic infection, Prognosis

\section{Background}

Infection represents one of the major complications associated with prosthetic aortic graft with a reported incidence ranging $0.5 \%$ to $2 \%$ [1]. It be could lower as demonstrated by Vogel et al. [2]. They studied 12,626 patients who underwent, between 1987 and 2005, open repair for abdominal aortic aneurysms. The 2-year rate of aortic graft infection was $0.19 \%$. The occurrence of bacteremia or surgical site infection during the index

\footnotetext{
* Correspondence: oleroy@ch-tourcoing.fr

${ }^{5}$ Service de Réanimation Médicale et Maladies Infectieuses, Hôpital Chatiliez, Rue du Président Coty, Tourcoing 59208, France

Full list of author information is available at the end of the article
}

hospitalization was significantly associated with the development of aortic graft infection.

The optimal management of aortic graft infection remains unclear and many questions on diagnosis, surgical management, and antibiotic therapy are unresolved [3]. For example, if the gold standard for surgical treatment is always graft explantation, the best techniques for reperfusion are unknown. The extra-anatomic bypassing technique using an axillofemoral graft was long considered the technique associated with the lower re-infection rate. It now appears than in situ revascularisation procedure could be more effective [4,5]. Nevertheless, uncertainty remains about the best graft for in situ replacement. The choice between normal graft, silver-coated polyester graft, rifampin- 
impregnated graft, allografts or autogenous vein could be difficult $[3,4]$.

Aortic graft infection is associated with considerable mortality and morbidity. In the Vogel et al. study, in-hospital mortality rate for patients readmitted for infection was $18 \%$ [2]. However, recent studies reported higher mortality rates [6]. To the best of our knowledge only a few studies reported factors associated with prognosis of patients suffering from aortic graft infection. We created in 2005 a multidisciplinary group including vascular surgeons, microbiologists, infectious diseases physicians, anesthesiologists and intensivists to optimize the management of patients with prosthetic vascular graft infection. This group has been managing a growing number of patients from public and private hospitals of the Nord-Pas de Calais area (4 millions of inhabitants), in the north of France. We reported in 2012 our experience about the first 85 evaluable patients treated in our center between 2005 and 2009 [7]. Given the lack of prognostic data about in-hospital outcome of patients suffering from aortic graft infection, our goal was to identify preoperative, intraoperative and postoperative characteristics of patients associated with poor outcome.

\section{Methods}

\section{Study population}

All patients admitted from January 2006 to October 2011 in the Intensive Care Unit (ICU), and the infectious diseases and surgical vascular departments of Tourcoing Hospital with a diagnosis of intra abdominal aortic graft infection were included in this retrospective study. In accordance with French law, approval of an Ethics Committee was not required for a cohort study that did not modify existing diagnosis or therapeutic strategies.

All patients had a previous aortofemoral or aortoiliac bypass. They were considered to suffer from definite intra abdominal aortic graft infection if at least two of the three following criteria were present: (a) clinical signs of infection either systemic (fever, chills, septic shock) or in the area of the prosthesis (i.e., enteric aortic fistula, intra-operative gross purulence, failure of graft incorporation), (b) biological signs of infection (C-reactive protein $>10 \mathrm{mg} / \mathrm{l}$, white blood count $>10,000 / \mathrm{mm}^{3}$ ) or radiological signs of infection (pathognomonic perigraft air or fluid, abscess) and (c) positive culture of intraoperative specimens or blood cultures (for potentially 'contaminant' pathogens such as coagulase-negative Staphylococcus, P. acnes or corynebacteria at least two intraoperative specimens or blood cultures or, at least one intraoperative specimen and one blood culture are required) [8].

\section{Surgical procedures and antimicrobial management}

All patients underwent a surgical procedure including complete debridement of devitalized and infected tissues around the prosthesis, total graft excision and in situ reconstruction or extra-anatomic bypass grafting.

Blood specimens for culture were drawn from all febrile patients (over $38.5^{\circ} \mathrm{C}$ ). Bacterial samples were collected intraoperatively. Multiple intraoperative samples were cultured on blood agar plates with standard aerobic and anaerobic methods. Antibiotic susceptibility patterns were interpreted in accordance with recommendations of the Comité de l'Antibiogramme de la Société Française de Microbiologie [9].

Empirical broad-spectrum intravenous antibiotic therapy was started immediately after intra-operative sampling and was secondarily adapted to microbiological results. In case of severe sepsis or septic shock, empirical therapy was started before surgical management, immediately after blood samples had been collected. Initial antimicrobial treatment was considered appropriate when all causative pathogens were in vitro susceptible to at least one of the antibiotics in the regimen. The duration of intravenous antimicrobial treatment was at least 6 weeks.

\section{Data collection and definitions}

On hospital admission, data about demographic characteristics, underlying diseases, prior vascular procedures, and biological findings were recorded.

Diabetes mellitus and chronic obstructive pulmonary diseases (COPD) were defined according to criteria proposed by the Expert Committee on the diagnosis and classification of diabetes mellitus and the American Thoracic Society, respectively [10,11]. A body mass index (BMI) $\geq 30 \mathrm{Kg} / \mathrm{m}^{2}$ defined obesity [12]. Immunosuppression included transplant, cancer, acquired immunodeficiency syndrome, immunosuppressive drugs and other immunodeficiency conditions. Risk of the surgical procedure was evaluated by the POSSUM score [13]. A classification of the preoperative physical status (ASA score) of the American Society of Anaesthesiologist was used for anaesthetic risk prediction [14].

Data about surgical management and intra-operative care were collected. They included type and duration of surgery, duration of aortic clamping, volume of intraoperative fluid administration and blood transfusion, and use of vasopressors.

On ICU admission, the severity of illness was assessed by the Simplified Acute Physiology score II (SAPS II), and the Sequential Organ Failure Assessment (SOFA) score $[15,16]$.

During ICU stay, we recorded data about the use and duration of mechanical ventilation, renal replacement therapy, vasopressors, and occurrence of complications. Septic shock, acute respiratory distress syndrome, acute renal failure or hospital acquired infections were defined according to usual criteria and categorized as medical 
complications. Vascular complications such as graft thrombosis, bleeding, or distal embolization were categorized as surgical complications.

\section{Outcome assessment}

The primary outcome was the in-hospital mortality rate, defined as any death, regardless of its cause, occurring within the hospitalization in our center.

\section{Statistical analysis}

Descriptive analyses were performed to check and resume data. Quantitative variables are reported as means \pm SD. Qualitative variables are reported as number and percentage. Continuous variables were compared using Student's $t$ test. When appropriate, continuous variables were analyzed as categorical variables using cut-points determined by method of box plots. Categorical variables were compared using the Chi-square test or Fisher's exact test when the Chi-square was not appropriate. Differences between groups were considered significant for variables yielding a $\mathrm{p}$ value $\leq 0.05$. No multivariate analysis was performed.

All statistical analyses were performed using SAS Software, V9.1.

\section{Results}

During the study period, 26 patients suffering from intra-abdominal aortic graft infection were admitted in our institution. One patient was not included due to missing data.

Main characteristics of patients on hospital admission are summarized in Table 1. All patients were male and most of them (96\%) had severe underlying diseases such as hypertension, coronary artery disease, COPD or obesity. Infection occurred within the 4 months following initial aortic graft surgery in 7 cases $(28 \%)$. Four of the 25 patients were admitted in ICU before surgical management.

Eight patients exhibiting on admission an anastomotic rupture underwent an emergency surgical procedure, one of whom died during surgery. The other 17 patients had elective surgery. An in situ prosthetic graft replacement was performed in all patients, excepted one who underwent an extra-anatomic bypass. Implanted aortic grafts were wrapped with omental flaps in 21 patients. Cryopreserved arterial allografts were mainly used $(n=$ 22/23). In 4 patients, with aorto-enteric fistula, an intestinal procedure was required. Durations of operation and aortic clamping, blood transfusions, colloid and crystalloid administration volumes and use of vasopressors are summarized in Table 2 .

Causative organisms of aortic graft infection were identified in 23 patients (92\%). Preoperative blood cultures were positive in 13 cases. In the remaining 10
Table 1 Preoperative characteristics of patients

\begin{tabular}{lc}
\hline Variables & \\
\hline Age (years) & $67 \pm 8.4$ \\
Comorbidities & \\
Obesity $\left(\mathrm{BMI}>30 \mathrm{~kg} / \mathrm{m}^{2}\right)$ & $11(44 \%)$ \\
Hypertension & $18(72 \%)$ \\
Coronary artery disease & $16(64 \%)$ \\
Diabetes mellitus & $4(16 \%)$ \\
COPD & $7(28 \%)$ \\
Immunosuppression & $6(24 \%)$ \\
ASA Score $\geq 3$ & $21(84 \%)$ \\
POSSUM score & $46.1 \pm 10.7$ \\
Preoperative severe sepsis & $7(28 \%)$ \\
Previous graft & \\
Aortounifemoral bypass graft/Dacron & $5(20 \%) / 5$ \\
Aortobifemoral bypass graft/Dacron & $14(56 \%) / 13$ \\
Aortobiiliac bypass/Dacron & $6(24 \%) / 6$ \\
Biological data & \\
Creatinine (mg/L) & $15.0 \pm 13.8$ \\
C Reactive Protein (mg/L) & $69.1 \pm 76.1$ \\
\hline
\end{tabular}

Data are expressed as mean \pm standard deviation values or numbers (\%) of patients.

cases, only bacterial cultures from intra-operative samples were positive. Thirty causative pathogens were isolated. In 8 patients, more than one pathogen was identified. Organisms were Gram positive cocci (methicillin susceptible $S$. aureus $\mathrm{n}=3$, methicillin resistant $S$. aureus $\mathrm{n}=2$, coagulase negative staphylococcus $\mathrm{n}=3$, Streptococcus spp. $\mathrm{n}=3$, Enterococcus spp. $\mathrm{n}=2$ ), Gram negative bacilli ( $E$. coli $\mathrm{n}=8$; enterobacteriaceae $\mathrm{n}=2$ ), Gram positive bacilli $(\mathrm{n}=3)$, anaerobes $(\mathrm{n}=2)$ and Candida spp. $(\mathrm{n}=2)$.

\section{Table 2 Intra-operative characteristics of patients}

\begin{tabular}{lc}
\hline Variables & \\
\hline Mean duration of operation (minutes) & $270 \pm 81$ \\
Mean duration of aortic clamping (minutes) & $118 \pm 50$ \\
Suprarenal aortic clamping & $6(24 \%)$ \\
Associated intestinal procedure & $4(16 \%)$ \\
Blood transfusion & $25(100 \%) / 5.7 \pm 2.1$ \\
$\quad$ Packed red cells (number of patients/units) & $21(84 \%) / 3.2 \pm 1.8$ \\
$\quad$ Fresh frozen plasma (number of patients/units) & $4(16 \%)$ \\
Platelets (number of patients) & $1020 \pm 549$ \\
Volume of intra-operative colloid administration (ml) & $3740 \pm 1280$ \\
Volume of intra-operative crystalloid administration (ml) & $20(80 \%)$ \\
\hline Use of vasopressor(s) & \\
\hline Data are expressed as mean &
\end{tabular}

Data are expressed as mean \pm standard deviation values or numbers (\%) of patients. 
Antimicrobial therapy was begun before surgical procedures in 17 cases (68\%) because either preoperative identification of causative organism(s) $(n=10)$ or preoperative presence of severe sepsis $(n=7)$. Most antimicrobial regimens included a wide spectrum betalactam (piperacillin-tazobactam $n=12$, imipenem $n=4$, 3rd generation cephalosporin $\mathrm{n}=3$ ) combined with an agent effective against methicillin-resistant staphylococcus spp. (glycopeptide $\mathrm{n}=16$, daptomycin $\mathrm{n}=3$, linezolid $\mathrm{n}=1$ ). Initial antimicrobial therapy was considered adequate in 22 patients (96\%).

After surgical procedures, 24 patients were admitted in the ICU. Main data about severity scores, vasopressors use, mechanical ventilation, and biological characteristics on ICU admission are reported Table 3. During ICU stay, 16 patients (67\%) developed medical complications, acute renal failure $(n=13)$, septic shock $(n=11)$, hospital-acquired infections $(n=5)$ and acute respiratory distress syndrome (ARDS) $(n=2)$. Renal replacement therapy was required for $12(50 \%)$ patients. The numbers of days without mechanical ventilation, vasopressors and/or renal replacement therapy on D28 for patients requiring such treatments are reported Table 3. Surgical complications occurred in 15 patients (63\%). Most frequent complications were bleeding $(n=8)$, graft thrombosis $(n=5)$, distal embolization $(n=4)$ and aortic graft-enteric fistula $(\mathrm{n}=1)$. Eight patients $(33 \%)$ underwent a secondary surgical procedure.

\begin{tabular}{lc}
$\begin{array}{l}\text { Table } \mathbf{3} \text { Characteristics of patients on ICU admission and } \\
\text { during ICU stay }\end{array}$ \\
\hline Variables \\
\hline On ICU admission \\
SAPS II & $47 \pm 16$ \\
SOFA Score & $8 \pm 4$ \\
Mechanical ventilation & $23(92 \%)$ \\
Use of vasopressor(s) & $13(54 \%)$ \\
Biological data & \\
$\quad$ Creatinine (mg/L) & $14.1 \pm 11.6$ \\
$\quad$ Lactate (mmol/L) & $3.0 \pm 2.5$ \\
C Reactive Protein (mg/L) & $123 \pm 84$ \\
$\quad$ PaO ${ }^{2} / F i O^{2}$ (mmHg) & $315 \pm 155$ \\
$\quad$ During ICU stay & $16(67 \%)$ \\
Occurrence of medical complications & $15(63 \%)$ \\
Occurrence of surgical complications & $10.3 \pm 10.6$ \\
Number of days without mechanical ventilation at D28* & $15.5 \pm 11.3$ \\
Number of days without use of vasopressors at D28* & $7.3 \pm 9.9$ \\
\hline Number of days without renal replacement therapy at D28*
\end{tabular}

Data are expressed as mean \pm standard deviation values or numbers (\%) of patients. *Determined in patients treated with mechanical ventilation, vasopressors and/or renal replacement therapy.
Ten patients died in ICU. The mean length of ICU stay for non survivors was $13.2 \pm 9.5$ days. Fourteen patients were transferred from the ICU to medical or surgical wards, $14 \pm 12$ days after ICU admission. Among them, one patient died before hospital discharge. The in-hospital mortality rate was thus $48 \%(12 / 25)$. Comparison of preoperative, intra-operative and post-operative patients' characteristics between in-hospital survivors and non survivors is reported Table 4. Among pre-operative characteristics, age $\geq 70$ years, creatinine $\geq 12 \mathrm{mg} / \mathrm{L}$ and $\mathrm{C}$ reactive protein $\geq 50 \mathrm{mg} / \mathrm{L}$ were significantly associated with in-hospital mortality. According to the number of these factors present on ICU admission, in hospital mortality rates were $0 \%$, $14.3 \%, 85.7 \%$ and $100 \%$ for $0,1,2$ and 3 factors, respectively. Interestingly, among the 12 patients $<70$ years, only one patient died during hospital stay and he had preoperative $13 \mathrm{mg} / \mathrm{l}$ creatinine and $235 \mathrm{mg} / \mathrm{L}$ C Reactive protein. Among the 13 patients, older than 70 years, 11 died during hospital stay. The 2 survivors had neither creatinine $\geq 12 \mathrm{mg} / \mathrm{L}$ nor $\mathrm{C}$ reactive protein $\geq 50 \mathrm{mg} / \mathrm{L}$. Among intraoperative characteristics, only an associated intestinal procedure was associated with prognosis. Finally, among post-operative characteristics, non survivors had higher SAPS II and SOFA Score on ICU admission and exhibited more frequent medical and/or surgical complications.

One year after hospital discharge, all patients were still alive without recurrence of infection.

\section{Discussion}

Twenty five patients suffering from intra-abdominal aortic graft infection were included in this retrospective study. All underwent graft excision. In-hospital morbidity and mortality were high. Prognostic analysis suggests that some characteristics of patients on hospital admission such as age and values of C-reactive protein and creatinine could predict in-hospital outcome.

In our series, postoperative complications occurred in $67 \%$ of patients and $48 \%$ of patients died during hospital stay. This mortality rate is in the high range on what is reported in the literature with mortality rates for aortic graft infection between 8 and 56.5\% [17-27]. Most published studies focused on surgical aspect of aortic graft infection treatment but only few reported exhaustive data on surgical patients underlying conditions. Finally, search for predictive factors of perioperative mortality was not performed in most studies.

In 2004, Kieffer et al. reported a series of 179 consecutive surgery patients, from 1988 to 2002, and observed a 20.1\% early postoperative mortality [22]. Batt among 82 consecutive aortic graft infection patients, from 2000 to 2008, found a $33 \%$ perioperative mortality rate [6]. The same author had reported in 2003 a lower perioperative death rate of $16.6 \%$ [21]. In our opinion, such discrepancies could only be explained by differences between patients undergoing 
Table 4 Bivariate analysis of factors associated with in-hospital death

\begin{tabular}{|c|c|c|c|}
\hline Variables & Survivors $(n=13)$ & Non survivors $(n=12)$ & $\mathbf{p}$ \\
\hline \multicolumn{4}{|l|}{ Pre-operative characteristics } \\
\hline Age (years) & $61.6 \pm 6.5$ & $74.5 \pm 3.5$ & 0.0006 \\
\hline Age $\geq 70$ years & 2 & 11 & 0.0002 \\
\hline Obesity (BMI > 30 kg/m²) & 4 & 7 & 0.43 \\
\hline Hypertension & 9 & 9 & 1 \\
\hline Coronary artery disease & 9 & 7 & 0.69 \\
\hline Diabetes mellitus & 3 & 1 & 0.6 \\
\hline COPD & 5 & 2 & 0.39 \\
\hline Immunosuppression & 3 & 3 & 1 \\
\hline ASA Score & $2.9 \pm 0.76$ & $3.5 \pm 0.67$ & 0.09 \\
\hline Possum Score & $42 \pm 44$ & $46 \pm 55$ & 0.06 \\
\hline Preoperative severe sepsis & 2 & 5 & 0.20 \\
\hline Creatinine (mg/L) & $10.4 \pm 4.6$ & $20.1 \pm 18.4$ & 0.03 \\
\hline Creatinine $\geq 12 \mathrm{mg} / \mathrm{L}$ & 3 & 9 & 0.02 \\
\hline C Reactive Protein (mg/L) & $16.0 \pm 26.0$ & $126.5 \pm 202.0$ & 0.006 \\
\hline C Reactive Protein $\geq 50 \mathrm{mg} / \mathrm{L}$ & 2 & 8 & 0.008 \\
\hline \multicolumn{4}{|l|}{ Intra-operative characteristics } \\
\hline Emergent surgical procedure for anastomotic rupture & 2 & 6 & 0.1 \\
\hline Mean duration of operation (minutes) & $273 \pm 70$ & $266 \pm 95$ & 0.70 \\
\hline Mean duration of aortic clamping (minutes) & $103 \pm 39$ & $136 \pm 57$ & 0.15 \\
\hline Suprarenal aortic clamping & 2 & 4 & 0.36 \\
\hline Associated intestinal procedure & 0 & 4 & 0.04 \\
\hline Number of packed red cells units & $5.3 \pm 1.2$ & $6.1 \pm 2.8$ & 0.51 \\
\hline Volume of intra-operative colloid administration (ml) & $961 \pm 518$ & $1083 \pm 596$ & 0.61 \\
\hline Volume of intra-operative crystalloid administration (ml) & $4003 \pm 924$ & $3454 \pm 1571$ & 0.33 \\
\hline Use of vasopressor(s) & 9 & 11 & 0.32 \\
\hline \multicolumn{4}{|l|}{ Post-operative characteristics } \\
\hline SAPS II on ICU admission & $40.5 \pm 8.2$ & $54.7 \pm 20.6$ & 0.10 \\
\hline SOFA Score on ICU admission & $6.5 \pm 3.7$ & $10.4 \pm 3.9$ & 0.05 \\
\hline Mechanical ventilation on ICU admission & 12 & 11 & 1 \\
\hline Use of vasopressor(s) on ICU admission & 5 & 8 & 0.12 \\
\hline \multicolumn{4}{|l|}{ Biological data on ICU admission } \\
\hline Creatinine (mg/L) & $11.2 \pm 4.4$ & $17.5 \pm 16.2$ & 0.25 \\
\hline Lactate $(\mathrm{mmol} / \mathrm{L})$ & $2.1 \pm 0.7$ & $4.0 \pm 3.5$ & 0.10 \\
\hline C Reactive Protein (mg/L) & $106.6 \pm 74.0$ & $142.3 \pm 97.0$ & 0.70 \\
\hline $\mathrm{PaO}^{2} / \mathrm{FiO}^{2}(\mathrm{mmHg})$ & $365.3 \pm 137.1$ & $260.1 \pm 160.7$ & 0.10 \\
\hline Occurrence of medical complications during ICU stay & 6 & 10 & 0.02 \\
\hline Occurrence of surgical complications during ICU stay & 5 & 10 & 0.01 \\
\hline Renal replacement therapy during ICU stay & 4 & 8 & 0.16 \\
\hline
\end{tabular}

Data are expressed as mean \pm standard deviation values or numbers (\%) of patients.

surgical procedures, particularly underlying diseases. In the 2003 Batt's study with $16.6 \%$ mortality, coronary artery disease, hypertension, diabetes mellitus, chronic obstructive pulmonary disease, were found in $36 \%, 41 \%, 14 \%$, and $22 \%$ of patients, respectively [21]. In our series, the incidence of these underlying diseases was quite higher since it was $64 \%$, $72 \%, 16 \%$, and $28 \%$, respectively and this might explain the differences in prognosis. 
Prognostic factors associated with early postoperative mortality reported by Kieffer et al. were septic shock, presence of aorto-enteric fistula, emergency surgery, emergency allograft replacement, surgical or medical complications, and need for repeat surgery [22]. In our study we searched for pre, intra or post operative factors associated with in-hospital mortality. Among postoperative factors, occurrence of medical or surgical complications was associated with poor outcome, as in Kieffer's study. SOFA score on ICU admission was also significantly higher in non survivors than in survivors. This score reflects organ failures occurring during surgery whereas septic shock reported by Kieffer fits only to hemodynamic failure. The single intra operative characteristic associated with prognosis was "associated intestinal procedure". This is similar to the presence of aorto-enteric fistula previously reported. Surprisingly, durations of operation and aortic clamping, suprarenal clamping, volume of colloid or crystalloid administration, number of packed red cell units and vasopressors use were not statistically different in survivors and non survivors. Finally, we found that three preoperative factors, age $\geq 70$ years, creatinine $\geq 12 \mathrm{mg} / \mathrm{L}$, and $C$ reactive protein $\geq 50 \mathrm{mg} / \mathrm{L}$ were associated with prognosis. The combination of these 3 prognostic factors seems interesting since in hospital mortality rate was $7.7 \%$ when no or only one factor was present and $91.6 \%$ when two or three factors were present. An age under 70 years could be a useful single factor to take in account as $91.6 \%$ of patients less than 70 years survived. Conversely, the survival rate of patients over 70 years was very low (15.4\%). The survivors among the older patients had neither creatinine $\geq 12 \mathrm{mg} / \mathrm{L}$ nor $C$ reactive protein $\geq 50 \mathrm{mg} / \mathrm{L}$. In our mind these data could be considered before any surgical approach of an aortic graft infection. A surgical procedure in older patients with either creatinine $\geq 12 \mathrm{mg} / \mathrm{L}$ or $C$ reactive protein $\geq 50 \mathrm{mg} / \mathrm{L}$ or both could be questionable. Long-term or lifelong suppressive antimicrobial therapy in patients who are not eligible for surgical device removal has been reported $[28,29]$ with partial success. Medical treatment could appear as the best choice in patients for which graft excision is associated with no, or very low in-hospital survival rate.

Our study has numerous limits. First of all, it is retrospective and performed in a single centre. Although data collection was retrospective, it was exhaustive and only one patient was excluded for lack of data. Second, the number of included patients is low with only 25 studied patients. Nevertheless, the number of patients included in numerous other studies is similar $[17,18,21,24,26]$. Finally, the value of our statistical analysis is limited as no multivariate analysis was performed. As underlined by Peduzzi and Concato, logistic regression analysis needs between 10 and 15 events per co variable [30]. As we observed 12 events (in-hospital deaths) in this series, no multivariate analysis could be performed. Nevertheless, as data about prognostic factors are scarce, we believe our results and particularly the impact of preoperative factors such as age, and values of $\mathrm{C}$ reactive protein and creatinine add to the knowledge of this disease. Obviously, our results must be evaluated in a prospective and, ideally, multicenter study including more patients.

\section{Conclusion}

In conclusion, morbidity and mortality associated with surgical approach of aortic graft infections are considerable. Age and values of creatinine and $C$ Reactive protein on hospital admission appear as the most important determinant of in hospital mortality and, consequently, of surgical strategy.

\section{Abbreviations}

ICU: Intensive care unit; COPD: Chronic obstructive pulmonary disease; BMI: Body mass index; MDRD: Modification of diet in renal disease; GFR: Glomerular filtration rate; POSSUM: Physiological and operative severity score for the enumeration of mortality; ASA: American Society of Anaesthesiology; SAPS: Simplified Acute Physiology Score; SOFA: Sepsisrelated organ failure assessment; SD: Standard deviation.

\section{Competing interests}

The authors declare that they have no competing interests.

\section{Authors' contributions}

MG collected data and helped to draft the manuscript, PYD participated in the design of the study, collected data and helped to draft the manuscript, AM collected data and helped to draft the manuscript, BSB collected data and helped to draft the manuscript, PVE collected data and helped to draft the manuscript, TE collected data and helped to draft the manuscript, PD performed the statistical analysis, and OL contributed to the design of the study and wrote the manuscript. All authors read and approved the final manuscript.

\section{Acknowledgment}

The writers thank G. Moran for collaboration in the writing of this paper.

\section{Author details}

${ }^{1}$ Service de Réanimation Médicale et Maladies Infectieuses, Hôpital Chatiliez Tourcoing 59, France. ${ }^{2}$ Service de chirurgie vasculaire, Hôpital Chatiliez, Tourcoing 59, France. ${ }^{3}$ Département d'anesthésie, Hôpital Chatiliez, Tourcoing 59, France. ${ }^{4}$ Département de bio statistiques, CHRU, Lille 59, France. ${ }^{5}$ Service de Réanimation Médicale et Maladies Infectieuses, Hôpital Chatiliez, Rue du Président Coty, Tourcoing 59208, France.

Received: 3 January 2014 Accepted: 7 April 2014

Published: 22 April 2014

\section{References}

1. Seeger JM: Management of patients with prosthetic vascular graft infection. Am Surg 2000, 66:166-177.

2. Vogel TR, Symons R, Flum DR: The incidence and factors associated with graft infection after aortic aneurysm repair. J Vasc Surg 2008, 47:264-269

3. FitzGerald SF, Kelly C, Humphreys $\mathrm{H}$ : Diagnosis and treatment of prosthetic aortic graft infections: confusion and inconsistency in the absence of evidence or consensus. J Antimicrob Chemother 2005, 56:996-999.

4. Pupka A, Skora J, Janczak D, Plonek T, Marczak J, Szydełko T: In situ revascularisation with silver-coated polyester prostheses and arterial homografts in patients with aortic graft infection-a prospective, comparative, single-centre study. Eur J Vasc Endovasc Surg 2011, 41:61-67. 
5. O'Connor S, Andrew P, Batt M, Becquemin JP: A systematic review and meta-analysis of treatments for aortic graft infection. J Vasc Surg 2006 44:38-45.

6. Batt M, Jean-Baptiste E, O'Connor S, Feugier P, Haulon S, Association Universitaire de Recherche en Chirurgie Vasculaire (AURC): Contemporary management of infrarenal aortic graft infection: early and late results in 82 patients. Vascular 2012, 20:129-137.

7. Legout L, Sarraz-Bournet B, D'Elia PV, Devos P, Pasquet A, Caillaux M, Wallet F, Yazdanpanah Y, Senneville E, Haulon S, Leroy O: Characteristics and prognosis in patients with prosthetic vascular graft infection: a prospective observational cohort study. Clin Microbiol Infect 2012, 18:352-358

8. Leroy O, Meybeck A, Sarraz-Bournet B, D'Elia P, Legout L: Vascular graft infections. Curr Opin Infect Dis 2012, 25:154-158.

9. Recommandations du Comité de l'Antibiogramme de la Société Française de Microbiologie. http://www.sfm-microbiologie.org.

10. Report of the Expert Committee on the Diagnosis and Classification of Diabetes Mellitus. Diabetes Care 1997, 20(7):1183-1197.

11. American Thoracic Society: Standards for the diagnosis and care of patients with chronic obstructive pulmonary disease. Am J Respir Crit Care Med 1995, 152(suppl 2):77-121.

12. Garrow JS, Webster J: Quetelet's index $(\mathrm{W} / \mathrm{H} 2)$ as a measure of fatness. Int J Obes 1985, 9:147-153.

13. Copeland GP, Jones D, Walters M: POSSUM: a scoring system for surgical audit. Br J Surg 1991, 78:356-360.

14. American Society of Anesthesiology: New classification of physical status. Anesthesiol 1963, 24:111-117.

15. Le Gall JR, Lemeshow S, Saulnier F: A new Simplified Acute Physiology Score (SAPS II) based on a European/North American multicenter study. JAMA 1993, 270:2957-2963.

16. Vincent $J$, Moreno R, Takala J, Willatts $S$, De Mendonça A, Bruining H, Reinhart CK, Suter PM, Thijs LG: The SOFA (Sepsis-related Organ Failure Assessment) score to describe organ dysfunction/failure. Intensive Care Med 1996, 22:707-710.

17. Young RM, Cherry KJ Jr, Davis PM, Gloviczki P, Bower TC, Panneton JM, Hallett JW Jr: The results of in situ prosthetic replacement for infected aortic grafts. Am J Surg 1999, 178:136-140.

18. Lesèche $G$, Castier $Y$, Petit MD, Bertrand P, Kitzis M, Mussot S, Besnard M, Cerceau O: Long-term results of cryopreserved arterial allograft reconstruction in infected prosthetic grafts and mycotic aneurysms of the abdominal aorta. J Vasc Surg 2001, 34:616-622.

19. Noel AA, Gloviczki P, Cherry KJ Jr, Safi H, Goldstone J, Morasch MD, Johansen $\mathrm{KH}$, United States Cryopreserved Aortic Allograft Registry: Abdominal aortic reconstruction in infected fields: early results of the United States cryopreserved aortic allograft registry. J Vasc Surg 2002, 35:847-852.

20. Chiesa R, Astore D, Frigerio S, Garriboli L, Piccolo G, Castellano R, Scalamogna M, Odero A, Pirrelli S, Biasi G, Mingazzini P, Biglioli P, Polvani G, Guarino A, Agrifoglio G, Tori A, Spina G: Vascular prosthetic graft infection: epidemiology, bacteriology, pathogenesis and treatment. Acta Chir Belg 2002, 102:238-247.

21. Batt M, Magne JL, Alric P, Muzj A, Ruotolo C, Ljungstrom KG, Garcia-Casas R, Simms M: In situ revascularization with silver-coated polyester grafts to treat aortic infection: early and midterm results. J Vasc Surg 2003, 38:983-989.

22. Kieffer E, Gomes D, Chiche L, Fléron M-H, Koskas F, Bahnini A: Allograft replacement for infrarenal aortic graft infection: early and late results in 179 patients. J Vasc Surg 2004, 39:1009-1017.

23. Pirrelli S, Arici V, Bozzani A, Odero A: Aortic graft infections: treatment with arterial allograft. Transplant Proc 2005, 37:2694-2696.

24. Kitamura T, Morota T, Motomura N, Ono M, Shibata K, Ueno K, Kotsuka Y, Takamoto S: Management of infected grafts and aneurysms of the aorta. Ann Vasc Surg 2005, 19:335-342.

25. Oderich GS, Bower TC, Cherry KJ Jr, Panneton JM, Sullivan TM, Noel AA, Carmo M, Cha S, Kalra M, Gloviczki P: Evolution from axillofemoral to in situ prosthetic reconstruction for the treatment of aortic graft infections at a single center. J Vasc Surg 2006, 43:1166-1174.

26. Batt M, Jean-Baptiste $E_{1} O^{\prime}$ Connor S, Bouillanne PJ, Haudebourg P, HassenKhodja R, Declemy S, Farhad R: In-situ revascularisation for patients with aortic graft infection: a single centre experience with silver coated polyester grafts. Eur J Vasc Endovasc Surg 2008, 36:182-188.
27. Saleem BR, Meerwaldt R, Tielliu IF, Verhoeven EL, van den Dungen JJ, Zeebregts CJ: Conservative treatment of vascular prosthetic graft infection is associated with high mortality. Am J Surg 2010, 200:47-52.

28. Roy D, Grove Dl: Efficacy of long-term antibiotic suppressive therapy in proven or suspected infected abdominal aortic grafts. J Infect 2000, 40:184-187.

29. Baddour LM, Infectious Diseases Society of America's Emerging Infections Network: Long-term suppressive antimicrobial therapy for intravascular device-related infections. Am J Med Sci 2001, 322:209-212.

30. Peduzzi P, Concato J, Kemper E, Holford TR, Feinstein AR: A simulation study of the number of events per variable in logistic regression analysis. J Clin Epidemiol 1996, 49:1373-1379.

doi:10.1186/1471-2334-14-215

Cite this article as: Garot et al.: Intra-abdominal aortic graft infection: prognostic factors associated with in-hospital mortality. BMC Infectious Diseases 2014 14:215.

\section{Submit your next manuscript to BioMed Central and take full advantage of:}

- Convenient online submission

- Thorough peer review

- No space constraints or color figure charges

- Immediate publication on acceptance

- Inclusion in PubMed, CAS, Scopus and Google Scholar

- Research which is freely available for redistribution

Submit your manuscript at www.biomedcentral.com/submit
C Biomed Central 